\title{
Entrevista com Gabriel Ignácio Anitua
}

Tamires Maria Alves e Gabriela Laura Gusis

\section{Gabriel Ignacio Anitua}

É Defensor Público Oficial perante os Tribunais Orais Criminais de Buenos Aires. É advogado, formado em direito e licenciado em sociologia pela Universidade de Buenos Aires. Realizou mestrado em "Sistema Penal e Problemas Sociais" pela Universidade de Buenos Aires. Também tem diploma de Estudos avançados em Direito Penal pela Universidade do País Basco (1999) e defendeu seu doutorado em 2003 na Universidade de Barcelona. É autor de extensa bibliografia, e a maioria de suas obras discorre sobre temáticas relacionadas ao direito penal destacando-se a sua grande obra "História dos Pensamentos Criminológicos" traduzida pela Editora Revan. ORCID: http://orcid.org/0000-0001-5182-6417 


\section{Entrevistadoras (Tamires Alves e Gabriela Gusis):}

Boa tarde, Gabriel. De antemão gostaríamos de agradecê-lo por nos receber para esta entrevista. Vamos começá-la pedindo para você discorrer um pouco sobre política. Nos últimos anos, tanto aqui na Argentina quanto no Brasil, tivemos governos ditos mais progressistas, de esquerda, e mesmo assim mantivemos o fenômeno do aumento das prisões, o chamado encarceramento em massa. O que você pensa sobre isso? Não se trata de um fenômeno divergente do que teóricos consagrados da criminologia, como Rusche e Kirchheimer, ou mesmo Wacquant falavam? Dizemos isso porque as ideias difundidas por estes eram de que o aumento das prisões estava vinculado as oscilações dos investimentos sociais. Entretanto, não foi isso que sucedeu nestes casos...

\section{Gabriel Anitua:}

Este é um fenômeno complexo que, mesmo para os muitos formados em criminologia crítica, em posições progressistas, nos preocupa e nos surpreende. Existem alguns trabalhos já realizados nesse sentido, como do Prof. Dr. Máximo Sozzo que comparou não somente a Argentina e o Brasil, também outros lugares, como o Equador e a Venezuela. Sozzo olhou para este mesmo fenômeno para tentar explicá-lo. Portanto, não tem ligação apenas com a orientação ideológica, como também com um certo bem-estar econômico, que parece ir de encontro as teses mais tradicionais da esquerda, de associar a uma maior exploração. Isso estava previsto nas mais antigas teses de Rusche e Kircheimer, que parecem também estar nesse sentido contrário. Provavelmente, estes governos mais progressistas, tampouco escaparam da nova orientação do capitalismo, que necessita criar uma classe subalterna que seja claramente identificável, mesmo que seja minoritária. Isso passa também nos governos que promulgam certo bem-estar a setores de classe média baixa, incluindo a baixa. Mas é necessário que sempre exista algum setor de autênticos excluídos, que é a população das prisões.

É complexo de observar, mesmo vendo o contrário. Penso agora mais nos Estados Unidos e Europa, nos períodos de recessão, e com governos mais neoliberais ou de direita, que reduziram as taxas carcerárias ou as frearam, como no caso dos Estados Unidos. Também e isso é confuso de dizer-, assim também não se cumpre a tese de Rusche. Por isso é importante estudar e tentar saber o que acontece para além da intervenção. Também é preciso fazer para frear e denunciar esse fenômeno.

Mas, primeiro há que se tentar estudar, explicar, saber o que se passa. Ver que não é necessariamente uma consequência do aumento das prisões. Muitas vezes tem a ver com não apresentar francos a crítica da direita. Estou pensando aqui no caso da Argentina e do Brasil o sistema político destes países são muito complexos. A direita talvez tenha mais facilidade em frear o aumento da punitividade porque não tem uma oposição com esta demagogia punitiva. Penso também no caso do Chile que quando um governo progressista obteve sucesso, a taxa de presos subiu, e já com a direita de Piñera ela não apenas freou como baixou. Claro, quem vai ganhar essa na direita do Chile? A esquerda não, mas o contrário sim. Isso também pode explicar este fenómeno. Por isso é algo muito complexo, claro que estou pensando aqui em hipóteses sem comprova-las. É preciso tentar validar, comprovar e ver o que se pode fazer para reduzir este fenômeno. No Brasil esse fenómeno já alcança cifras mais que preocupantes, e isso é um autêntico genocídio. $E$ vai para além da população reclusa, como também para os que têm pedidos de captura, os que estão em prisões domiciliares. Todos estes são uma enorme população controlada ou controlável no Brasil.

Então, é sobre isso que falo, existem trabalhos sérios, como essa investigação que fez o 
Sozzo, que inclusive demonstram que nem tudo é linear. O caso da Argentina também é notório, de como estacionou o crescimento da população presa entre 2004 e 2005, por este tempo pelo menos freou, depois seguiu crescendo. Ou mesmo o caso do Equador, que com políticas claras de anistia, de indulto generalizado em relação as drogas, também foram capazes de baixar bastante os índices carcerários, mas depois disso desfeito, seguiram subindo. Essa lógica do punitivismo aparece na América Latina para além dos espectros de esquerda ou direita, progressismo ou não, bem-estar econômico ou mal-estar econômico. Aparece como uma lógica que se impôs, creio que a partir dos anos 1990, e que às vezes freia, mas na maioria das vezes cresce, e que está deixando marcas em nossos países.

\section{Entrevistadoras:}

Sim, é isso. Porque temos uma lógica nesses governos de desenvolvimento, então existem também investimentos na questão social. Todavia os índices prisionais seguem subindo muitíssimo. Mais até do que nos Estados Unidos e na China, que hoje são os primeiros países no ranking do encarceramento.

\section{Gabriel Anitua:}

Sim, é preocupante. Além disso, somado a esse cenário, com agora a participa- ção de governos reacionários, mais de direita, o espectro piora porque esses governos já têm estes altos números de presos, e impõe, provavelmente, piores condições de vida nas prisões. Penso no caso argentino, porque mesmo com o aumento do número de presos, pelo menos havia um discurso sobre a intensão de melhorar a situação em que se encontram as prisões. Agora não, ninguém pensa em criar prisões para diminuir a superlotação, ou melhorar a alimentação, as condições de estudos, ou a promulgação de direitos sociais nos próprios cárceres. Portanto, isso vai ser mais duro, vai ser qualitativamente pior, não apenas quantitativamente pior. Então, não se pioram apenas os números absolutos de presos, mas também as condições materiais em que estes se encontram. De que cárceres estamos falando? De cárceres piores.

\section{Entrevistadoras:}

Agora estamos enfrentando, com Macri na Argentina, Brasil com Temer, e Chile com Piñera, governos mais à direita, que tem políticas públicas de segurança mais problemáticas. Nestes últimos tempos, Patricia Bullrich na Argentina falou sobre a Doutrina Chocobar, como uma doutrina boa, onde a polícia poderia defender-se, ao não ser sempre culpável, dizendo que as ações executadas pela mesma são de legítima defesa, enquanto seguimos assistindo ao assassinato de jovens pobres, como Facundo, que morreu com apenas 11 anos, em Tucumán e Raphael Nahuel, um jovem mapuche morto também recentemente. No Brasil, nós começamos agora uma intervenção militar no Estado do Rio de Janeiro, e também já adotamos políticas públicas que permitiam que as abordagens policiais que matassem sujeitos, poderiam ser absolvidas caso fossem entendidas como legítima defesa. O que você pensa deste momento que a América latina vem vivendo?

\section{Gabriel Anitua:}

Olha, eu tentaria não generalizar, porque creio que são problemas distintos. O caso é que sempre trata-se da direita, são marcos econômicos similares entre Piñera, Temer e Macri. Agora, justamente em matéria de políticas concretas e políticas de segurança emplacadas em determinados locais concretos, creio que há diferenças. No caso do Chile, por exemplo, há provavelmente e um capitalismo mais hegemônico, não há disputas na própria coalização dominante, e, portanto, podem fazer políticas mais coerentes. Como eu dizia antes para vocês, podem reduzir o número de presos, podem fazer uma reforma judicial e policial 
também, até mesmo dirigida com orientação. Isso no Brasil ou na Argentina seria muito mais complexo, por exemplo. O exemplo da intervenção militar que vocês disseram que está ocorrendo no Rio de Janeiro, mostra isso. Porque dentro desta coalisão dominante, há também disputas. O problema não é só que governos de direita querem fazer tal coisa, e nós, que estamos mais próximos de ideias progressistas, nos opomos. Não. Essa coalização de direita tem uma série de posicionamentos particulares que eles não concordam.

Por exemplo, na Argentina é muito clara a disputa entre setores vinculados aos serviços de inteligência, setores que entregam ao autogoverno da polícia, os setores que respondem a Bullrich, setores que tentam a reforma mais liberal e estão mais próximos ao Ministério da Justiça etc. Há entre eles enormes disputas que são, seguramente, para eles, mais importantes do que as críticas que nós da academia ou dos setores de oposição, lhes podemos fazer. No Brasil também acontece isso, e é um problema porque então, mesmo que haja mais mortos, mais violência e mais incoerência, ainda assim vão mais adiante estas políticas. Um exemplo claro foi este caso desgraçado no Rio de Janeiro, onde morreu a vereadora Marielle Franco. Uma lutadora dos direitos humanos, uma política assassinada. Por quem foi assassinada? Isso é preciso se tentar saber para se dizer para quem está nas posições dominantes: "bom, se vocês executam políticas públicas ruins, pelo menos as executem com maestria, não permitam que esse tipo de acontecimento ocorra, porque podem existir disputas entre a polícia e o exército, e isso vai trazer baixas, vão ter mortos entre nós". É isso o que diz Eugênio Raúl Zaffaroni, cuidado porque os mortos quem coloca somos nós.

Precisamos ser cautelosos, exigir incluso que, mesmo que façam essas políticas marcadas pelo neoliberalismo, por ideias repressivas ou de direita, que façam com cuidado, que façam isso bem. Porque os mortos sempre são dos setores mais compro- metidos, dos setores populares, e normalmente os que menos contam, que são pobres, não tem nome. E não são apenas os que vocês mencionaram os nomes, existem muitas vítimas, todos os dias. $E$ isso tem muito a ver com essas incoerências de se levar adiante algumas políticas. $E$ me parece que para criticá-las, é preciso restringir o olhar. Dizer "bom, aqui há um problema político, no Rio de Janeiro, referente as armas da polícia". Vamos nos encarregar disso.

Acredito que quanto menor e mais delimitado melhor. Porque se vamos criticar a política neoliberal, vamos estar de acordo quanto essas críticas, mas é necessário mudar o dia a dia. Sobre a atuação policial, neste caso do exército nas ruas no Brasil, vamos tentar ser concretos e pensar nas exigências que podemos fazer nestes casos. É necessário que os governos ao menos dirijam os seus subalternos, que dirijam os seus distintos autores, que eles não improvisem políticas. Meu temor sobre isto é grande, principalmente no Brasil e na Argentina. Também no Chile, é claro, mas o Chile é um país menor, mais unitário. Nossos países são muito complexos porque há forças que se embatem, forças públicas, federais, forças policiais em guerras com outras. Há muitos atores e isso é complexo, não há como simplificar. Não se deve dizer "a culpa toda é do governo Temer e do neoliberalismo". Mesmo que no governo Temer hajam sujeitos piores que outros, mas melhor que existam todos estes cargos do que as forças policiais se enfrentem e com isso passem a se matar. Até porque, neste caso, sobretudo estão matando pobres e negros.

\section{Entrevistadoras:}

Na Argentina vocês tiveram o caso do desaparecido Santiago Maldonado em 2017. Ele era um jovem que lutava pela causa mapuche. Nós em 2013 tivemos o caso do pedreiro Amarildo, um homem negro, pobre, que vivia numa favela brasileira. O que podemos pensar a respeito de se viver em estados que se dizem democráticos, mas que tem essas 
desaparições típicas de Estados de exceção?

\section{Gabriel Anitua:}

Me parece que podemos tirar algo positivo dessas experiências que foi a reação popular contra as desaparições, nas quais pediam a aparição com vida de Santiago Maldonado. Houve uma rejeição popular quase que majoritariamente eu diria. As pessoas saíram pelas ruas reivindicando, estavam preocupados. Isso é bom para marcar em primeiro lugar o governo, mas também as distintas forças, neste caso a gendermeria. Aos policiais dissemos "Olhem, nem tudo vocês podem fazer. Nós vamos estar atentos, vamos protestar, vamos relacionar este tipo de violência de um governo democrático com violências engendradas por governos ditatoriais", e essa resistência da população me parece positiva.

O negativo é que estes atores se atrevam a fazer isso. Se atrevam a fazer isso com essa legitimação que possuem, no caso argentino a gendermeria por muitos anos se mostrava como algo distinto da polícia. Por que? Porque eram vistos como uma instituição não corrupta, então podiam fazer qualquer coisa. E isso está caindo por terra, parte porque no governo atual a genderemeria já atua de uma maneira tão vulgar que até mesmo este prestígio que eles tinham nas classes mais populares, de não serem corruptos, eles estão perdendo. Negativo também é este respaldo que o governo dá a gendermeria, ao autogoverno, as policiais, ao exército, a estas distintas forças. É como se o governo reconhecesse "olha eu não posso fazer nada", enquanto os governos anteriores freavam as atuações destas instituições, abriam investigações, inquéritos. Este governo expressa o seu discurso como: "Nós vamos suportar o que quer que a polícia faça. A polícia é a nossa polícia e a gendermeria é a nossa gendermería, então tudo o que eles fazem está bem". Isso é o mais negativo e o mais perigoso que podem fazer porque estimulam a autonomia destas instituições e de seus atores. A autonomia da força policial é algo a se temer, no governo Temer, Macri, nas direitas, e até nas demais democracias. Mas isso os legitima solenemente quando dizem "vocês podem fazer o que quiserem que nós vamos lhes apoiar sempre. Nunca haverá investigação". Isso é o mais perigoso desses episódios que você mencionou e também da doutrina Chocobar.

Pobre policial este Chocobar, ficou famoso com essa expressão tão terrível que tem a ver com a sua atuação, porque matou pelas costas uma pessoa que fugia. Mas sobretudo tem a ver com o que fez a ministra Bullrich e em parte também o presidente Macri ao dizer "até mesmo isso que todos viram pela televisão, e que parece insustentável com o direito e com qualquer investigação imparcial da justiça, até mesmo nisso nós vamos dar o nosso aval. Inclusive nisso nós vamos sustentar a polícia como boa e os bandidos como os maus". Então com estas prerrogativas eles autorizaram inclusive a pena de norte extrajudicial. $E$ isso tem uma gravidade nos discursos de direitos. Isso é o anti-direito, o que a ministra de segurança e o presidente validam, e isso tem um alcance terrível. Esse discurso vindo do estado de direito e também é dito pelas forças policiais. O que estão dizendo é: "vocês podem fazer qualquer coisa". E nós temos vistos outros exemplos depois deste, como o do jovem Facundo, assassinado em Tucuman faz poucos dias. Existem vários fatos que podem ser ligados à polícia recebem permissão. Nós estamos recebendo esta mensagem, um aviso trapaceiro por parte dos políticos utilitaristas, porque o que irão proteger hoje podem muito bem amanhã se tiverem que usar a polícia como fuzil ou escudo, irão usar. Se escutarmos o que os comunicadores sociais e os políticos dizem é o seguinte: "Muito bem. Aplausos para o policial que matou mais um delinquente!". Bom, isso os policiais vão dizer e os meios vão replicar. E isso me parece o mais perigoso, essa consequência concreta, material, da permissão que há em não respeitar os direitos humanos para matar diretamente. 


\section{Entrevistadoras:}

Sim, claro. E ainda o que mais nos espanta é o resultado disso, ou seja, o que mais ouvimos nas ruas são frases como: "nós queremos os bandidos presos e mortos. São vocês que defendem os bandidos, são os defensores de direitos humanos que estão todo o tempo defendendo os delinquentes". E não é disso que estamos falando, estamos. Acreditamos que os direitos humanos estão muito mal amparados. Tanto pelo que ouvimos dos discursos policiais, midiáticos, dos governantes e da sociedade civil, principalmente as falas das camadas mais pobres da população. É difícil isso porque, sobretudo com a terrível cobertura midiática, indivíduos determinados são culpabilizados pela violência que é estrutural.

\section{Gabriel Anitua:}

Exatamente. Eu não sei o caso do Brasil, mas na Argentina há uma grande resistência mesmo no período democrático aos direitos humanos. Muitas pessoas que haviam apoiado a ditadura militar e durante anos se mantiveram ocultas porque era uma vergonha admiti-lo, não se podia dizer isso, hoje se atrevem a dizer: esse discurso de direitos humanos foi o que possibilitou condenar os militares envolvidos na ditadura e até mesmo os civis que colaboraram, e com isso não estamos de acordo". E agora com o advento dessa onda reacionário eles se atrevem a dizer isto. Eu digo isso porque não creio que todos os governos e coalizões de direita, todos os que votam na direita, compartilham destas ideias. O problemático é que quem compartilha destas ideias se sente representado por este governo, e se atrevem a dizer essas coisas que antes não diziam por vergonha.

E com isso se passam muitas coisas, algumas me parecem bastantes preocupantes agora. No caso do Brasil, por exemplo, é ainda mais complexo porque vocês não passaram por este processo de vergonha intensa. Haviam pessoas que apoiaram a ditadura e continuaram dizendo. Na Argentina não, aparentemente se você perguntava, $95 \%$ da população depois que a ditadura acabou, pareciam ter sempre sido contra. Isso eu acredito que era falso, assim como o governo ditatorial teve apoio civil, esse apoio dos cidadãos ficou escondido depois, envergonhado, e agora está ressurgindo de alguma maneira. Se está tornando transparente esse fascismo social, agora ele é mais visível.

\section{Entrevistadoras:}

E acreditamos que esse processo de vergonha de admitir que apoiaram a ditadura foi muito mais forte na Argentina porque vocês tiveram uma ditadura por mais tempo e pior...

\section{Gabriel Anitua:}

Pior e perdedora também. Como existiu a guerra das Malvinas, nós tivemos uma derrota. Uma derrota não, não podemos chamar assim, uma vitória que não foi encabeçada por nós argentinos, por conta de todo este contexto. Mas isso fez com que isso gerasse vergonha mesmo aos que apoiavam a ditadura tacitamente. Isso também não aconteceu no Brasil.

\section{Entrevistadoras:}

Sim, claro. E acreditamos que aqui vocês estudaram e tiveram muito mais acesso ao que aconteceu de fato nos bastidores da ditadura. Toda a população sabe como as pessoas sofreram, até hoje as mães e as avós da praça de maio fazem os eventos as quintas-feiras para manter viva a memória dos mortos e desaparecidos. Vocês falam sobre a ditadura todo o tempo, é uma memória muito viva, como se isso nunca tivesse saído da mente dos argentinos. Sempre existem novas notícias dos netos encontrados e a comemoração que segue estes tipos de vitórias... 


\section{Gabriel Anitua:}

A própria investigação e o julgamento penal tem muito a ver com isso. Eu discuto muito os efeitos da pena e nisso não compartilho com o ceticismo de Zaffaroni. Acredito que existe um efeito importante o juízo penal. O juízo dos anos 1980, contra as juntas militares e os julgamentos mais recentes dos militares tiveram efeitos importantes na população. Nos anos 1980 os julgamentos foram importantes para as pessoas mais velhas, todavia os mais recentes foram de extrema relevância para a população mais jovem, isso é notável, como perceberam negativamente à ditadura, aos militares e aos civis que foram cúmplices. $E$ isso me parece que é um efeito da visibilidade, ou seja, a publicidade sobre o juízo foi importante. Isso vocês não tiveram no Brasil, até porque poucos países tiveram.

\section{Entrevistadoras:}

Sim, claro. No Brasil, tivemos um pouco dessa averiguação da ditadura no governo de Dilma Rousseff, através da Comissão da Verdade. Esta fazia com que os genocidas falassem o que fizeram com os desaparecidos, como atuavam, onde colocaram os corpos, etc., mas nem perto das proporções que vocês tiveram na Argentina.

\section{Gabriel Anitua:}

Sim, mas aqui tivemos juízos de verdade onde castigos eram determinados. Então não era apenas uma averiguação do que passou, não havia anistia, os sujeitos tinham que defenderse do que fizeram.

\section{Entrevistadoras:}

Sim, é verdade, no Brasil a investigação veio tardia através da Comissão da Verdade em 2014 e muitos dos crimes, mesmo após o fim da ditadura, continuaram a ser executados. Isso mostra como mesmo quando a democracia começou, os sujeitos que se opunham à ditadura militar continuaram a desaparecer neste período democrático inaugurado. Então se sustentou a obscuridade sobre os crimes da ditadura cometidos no Brasil, mesmo depois do advento da democracia no território brasileiro.

\section{Gabriel Anitua:}

E é uma obscuridade muito complexa porque o Brasil também é um país muito maior que a Argentina. Seguramente as práticas ditatoriais foram muito diferentes de um estado para o outro. E até por isso eu não me atrevo a falar muito sobre este processo, porque é algo que não me compete.

\section{Entrevistadoras:}

No Brasil hoje nós vivemos um fenómeno complexo de prender pessoas que tem mais capital e influencia. Estamos vivenciando a prisão de políticos, donos de construtoras, indivíduos que fraudaram licitações, típicos crimes de colarinho branco. Esta operação que está ocorrendo no Brasil se chama "Operação Lava a Jato". O problema é que nesta operação se difunde uma falsa ideia de que agora que pessoas mais abastadas estão sendo presas, não apenas miseráveis e negros, finalmente a justiça penal estaria funcionando. Gostaríamos de saber o que você pensa sobre este fenómeno?

\section{Gabriel Anitua:}

Creio que isso tem a ver com essa nova dimensão comunicacional da democracia, que deixa de pensar em classes sociais e interesses concretos e apela para as pessoas, pro vizinho, a esses grupos pouco definidos, que podem corresponder com a classe média que fica indignada com os delitos. E essa classe média se indigna porque se considera vítima. Vítima 
dos pobres que roubam que furtam, e também vítimas dos ricos, dos políticos, e, sobretudo, das classes empresariais que também nos roubam.

Isso deveria ser denunciado como uma grande mentira. Eu acredito que é uma tarefa importante denunciar esta mentira evidente, divulgada pelos meios de comunicação para adular o seu público. Público este que é majoritariamente composto pela classe média. E é uma mentira porque é falso que todos os pobres roubem por consequência da pobreza, como também é falso que todos os setores mais empoderados económicamente o una política delinquam. E sobretudo é mentira que a clase média não comete delitos e que ela apenas seja vítima. Nós temos sempre que mostrar os inúmeros crimes que a classe média comete, e que, portanto, faz vítimas. Por exemplo, quem comete os crimes de transito, os culposos? São os que tem automóveis, não são os miseráveis e nem os milionários. Quem comete os delitos de gênero? Todas as clases sociais e, especialmente, as classes médias. Crimes económicos também, claro que em proporções muito distintas das elencadas na Operação Lava a Jato em números de reais, mas todas as classes médias, seja a brasileira ou a argentina, também se orgulham de pagar o menos possível. Estes indivíduos costumam dizer "não me entregue a fatura, eu te pago menos, desde que seja em dinheiro".

Por isso, é necessário começar a denunciar essa suposta inocência o vitimismo da classe média, porque me parece que é uma tarefa interessante do ponto de vista académico. $\mathrm{E}$ também é importante do ponto de vista político, isso é dizer, como dizia Sutherlandii na sua obra, quando discorria sobre os crimes de colarinho branco, dizia: "Bom, o delinquente pode ser qualquer um de nós. Não há nenhum caráter determinado, nem entre os pobres e nem entre os ricos de quem têm mais predisposição para delinquir. Vamos começar a estuda-los como um caráter social". Isso deve ser feito, sobretudo para evitarmos soluções fáceis. 0 maior perigo do poder penal é apresentar- se como uma solução sucinta e fácil para resolver todos os problemas. Isso é justamente o que dizem os meios de comunicação, e o que aceitam as classes médias: "que sejam todos presos". Mas devemos nos perguntar: todos presos para que? Que solução política é essa? É necessário começar a denunciar o poder penal como uma falácia, como algo que não soluciona nenhum problema.

$E$ isso todo é bastante complicado porque também há que se dirigir a classe média, que é muito hipócrita, que não quer se inteirar da realidade e muito menos se sentir parte do conflito, parte do problema. A classe média quer se sentir vítima e reclamar, fazendo queixas constantes a não se sabe quem, e afirmando sempre que os conhecidos bodes expiatórios estão em dívida com ela. Normalmente estes bodes expiatórios são os pobres, e seguem sendo os pobres que morrem. É claro que também existem alguns, mesmo que poucos, que também perdem com a justiça penal, alguns poderosos, políticos, empresários, etc. Mas chega a estes setores provavelmente a mesma ideia despendida de buscar os bodes expiatórios, de limpar a culpa de todos nestes sujeitos. Isso é preciso se denunciar para podermos enfrentar a lógica punitiva.

\section{Entrevistadoras:}

Sim, é exatamente isso que passa no Brasil hoje. As pessoas acreditam que agora que prendem os ricos e a justiça funciona, então vale a pena prender mais e mais até se limpar "toda essa sujeira que está aí". Mas não é apenas isso que acontece, ao se prender uma pessoa abastada vão se legitimando mil de prisões de jovens pobres.

\section{Gabriel Anitua:}

Muito mais, muito mais. $E$ isso é um grande novelo de como a justiça também se adere a 
essa lógica da indignação seletiva, através dos discursos dos meios de comunicação, nos quais a classe média reclama e cai nas armadilhas do poder punitivo. Assim como a classe médio a ideia de justiça também cai nessa trapaça, porque o objeto da justiça penal deve ser um objeto de participação política, e não é isso que faz hoje que deveria fazer. Esse hiperencarceramento, no final não nos vale de nada. Pode parecer que prender mais pessoas vá ajudar, caso elas sejam mais ricas, mas ao final não há como legitimar esse processo porque não funciona. Vamos relembrar a situação da Itália em 1990, a Lava Jato se assemelha muito a Mani Puliteiii. E essa história nós já conhecemos, ela termina mal, também para os juízes. Tenham cuidado, a cautela é muito importante. Uma solução rápida que parece efetiva num primeiro momento, mas logo depois vai se mostrar inconveniente com a própria legitimidade da justiça. Isso porque essa ideia tem pés de barro, ou seja, não tem suas bases firmes, não vai solucionar nenhum problema.

\section{Entrevistadoras:}

Bom, agora gostaríamos de te fazer uma pregunta sobre as manifestações que vocês tiveram na Argentina em 2017 referentes ao 2x1. Vocês tinham uma política na Argentina a respeito das prisões preventivas, e esse ano tiveram manifestações populares muito grandes para que esta política de 2x1 não fossse aplicável ao genoci- das da ditadura sobre os crimes de lesa humanidade. Você poderia nos explicar um pouco de como funcionava esta política do $2 \times 1$; porquê a a população não aceitou que mantivessem essa aplicação para os genocidas e por que o governo Macri gostaria de colocá-la em prática?

\section{Gabriel Anitua:}

A política do 2x1 esteve vigente por muito pouco tempo, justamente nos anos 1990 quando enfrentavamos a primeira crise de sobrepopulação. Essa solução foi pensada pelo governo de Carlos Menem para reducir esse número de presos, e, sobretudo de presos preventivos. Seria uma forma de castigar o Estado e premiar aos que foram arrastados para a prisão preventiva, de maneira que essa lei computava o dobro do tempo pasado na prisão, depois de dois anos de prisão preventiva. Então

95 Operação Mãos Limpas realizada na Itália em 1992, investigou políticos, empresários, mas principalmente os setores mais à esquerda. Prendeu 2993 pessoas e inseriu o país numa das suas maiores crises econômicas e políticas já enfrentadas. Se uma pessoa passasse mais de dois anos em prisão preventiva passava a se computador o dobro do tempo dos dias que passou reclusa. Era uma forma de tentar conseguir diminuir o número de presos nos anos 1990. Mas rapidamente essa lei saiu de cena, a lógica punitiva reclamou que inclusive era necessário prender mais gente. O efeito direto dessa reação foi que rapidamente o número de presos entre os anos 1998 - 2004 cresceu muitíssimo. Então, essa lei se findou ai nos anos 1990 e beneficiou alguns presos que estavam neste momento encarcerados neste momento, mas logo depois cessou.

A armadilha que agora quiseram articular junto aos que respondem por crimes de lesa humanidade, é que dizem: "a lei do 2x1 corresponde para eles porque nos anos 1990 eles já haviam cometido os delitos pelos quais são acusados, já que estes são dos anos 1970. Mesmo que não estivessem presos nessa época, a lei debe ser aplicada a eles porque já estavam sendo investigados". E essa justificativa é absurda. Um absurdo total. Mas em alguns casos baseado nisto foram sancionados, chegou até a Corte Suprema no ano passado e alguns sancionaram dizendo "bom, isso realmente pode ser aplicado a este senhor" e então reduziram os números de condenações.

Aqui, novamente, o que houve de mais positivo foi a reação da população, todos, inclusive a casse média, saíram pela praça de maio e pelas demais ruas gritando: "Isso nós não 
queremos. Não queremos arguições nem armadilhas legais para beneficiar os genocidas". E alguns representantes do governo queriam fazer isso e a maioria da população não lhes permitiu, nem a justiça nem o governo de abrandarem esas penas. Como alguns disseram: "não sobre este assunto!", que é muito sensível, e as vezes parece ser reduzido ao consenso mas que segue tendo a ampla maioria das pessoas não querendo indultar ou perdoar os responsáveis dessa ditadura e genocidio que ocorreram aquí.

\section{Entrevistadoras:}

E os crimes de lesa humanidade aquí tem penas perpetuas? Estes sujeitos vão morrer nos cárceres?

\section{Gabriel Anitua:}

Essa é outra discussão também a respeito dos castigos que podem ser aplicados de maneira "benéfica" para os envolvidos, como é o caso das prisões domiciliares, que é o que o governo tem tentado fazer agora. Mas há muita gente que se opoe a isso porque dizem "bom, se tem tanta gente de idade que não está bem e morrem nos presídios, é justo que esses que fizeram parte da dituadura também morram nos cárceres". E agora estão tentando fazer com que isso não ocorra, e então criam- se discursos humanistas para que não se tolere que isso ocorra. Para mim o mais importante que sucedeu foram os juizos que disseram: "Isso que vocês fizeram foi muito ruim e merecem uma condenção perpétua; ou uma condenação de 40 anos".

Não me importa se vão morrer nas suas casas ou nos cárceres. Mas entendo que há vítimas e setores sociais que para eles parece ruim que isso seja feito de maneira branda para estes sujeitos. Sobretudo porque há a comparação: "bom, porque com eles se tem penas brandas e conozco não? Porque todos os pobres que vão para os presídios e podem morrer lá não Ihes dão penas brandas e a esses que cometeram delitos mais tenebrosos nao? Se todas as cadeias fossem humanitarias, para todas as mulheres, para os país que cuidam dos filhos, para os aposentados. . . Se todos tivessem acesso a esas medidas, ótimo, então provavelmente ela também poderia ser aplicada aos genocidas. Mas parece um privilégio para eles isso".

Mas tudo isso é mito complexo porque todavía nós não defendemos nenhuma utilidade para o castigo diario. A prisão para mim tanto faz, não quer dizer que desejo que morram em uma unidade prisional.

\section{Entrevistadoras:}

Gabriel, tanto aqui quanto no Brasil estamos agora tendo discussões a respeito da redução da maioridade penal. No Brasil se verssa sobre reduzir de 18 para 16 anos. Aqui o que vocês pretendem reduzir é a privação de liberdade para jovens até 14 anos, o que no Brasil já temos previsto para crianças a partir dos 12 anos. Então no Brasil clocamos nestas instituições destinadas para os jovens, os que tenham entre 12 e 18 anos e depois nas cadeias para maiores de idade. Aqui vocês têm prisões de adultos a partir dos 18 e casas para menores de idade a partir dos 16 anos e tentam diminuir para 14 anos. Qual sua opinião sobre isso?

\section{Gabriel Anitua:}

Olha, nós temos um regime especial de toda forma. Já temos este regime dos 16 aos 18 anos e agora tentam baixar para os 14 anos de idade. Penso eu que há sim uma dívida em relação aos delitos cometidos nessa idade e é preciso pensar o que fazer nesta etapa tao 
crítica. Digo isso porque normalmente os que estão envolvidos em conflitos na rua com a polícia são adolescentes, são jovens, então é preciso se pensar. Mas o que acontece é que não estamos pensando em nada. Cada vez mais se buscam soluções mágicas no poder penal, querem castigar estes jovens como se fossem adultos e seguir adiante. Seguir adiante como? Essa não é a solução. Se é necessário se discutir a questão dos meninos e das meninas e adolescentes que estão em conflito com a políciae com a própria lei, vamos fazêlo, mas simplificar essa discussão sendo mai punitivos e mais duros não melhora nada. Isso é apenas um disfarce para a discussão. Esso é o que tem o poder punitivo com a lógica midiática, política, demagógica, que os leva a dizer isso, reduzindo a questão sem resolve-la, estaremos fadados a apenas repeti-la.

\section{Entrevistadoras:}

Ambas parcerias público privadas dentro dos complexos penitenciários e da segurança pública. Os preços dos presos nestes são muito mais elevados, mas o que dizem é que são unidades melhores e menos violentas. Sabemos que na Argentina não existem ainda estas prisões, embora no Brasil á tenhamos. O que você pensa deste fenômeno do capital privado na segurança?

\section{Gabriel Anitua:}

Na Argentina não existem prisões privadas, mas o capital privado que fazer negó- cio com tudo. Evidentemente construir cárceres ou prover alimentação e medicamentos para estas é um negócio também e isso também acontece aqui na Argentina. Muitas vezes estes cárceres estão ligados também a corrupção. As empresas asseguram que promoverão alimentos para os presídios, que muitas vezes são estatais, mas a entrega de alimentos não. Então mesmo que os cárceres não sejam privados, há fenômenos de privatização de serviços dentro delas. O capitalismo se pretende ser desligado do Estado, mas está sempre vinculado ao Estado, e faz os melhores negócios com o Estado, e isso também é a maneira como a corrupção se sustenta. Como podemos impedir isso? Basicamente com maiores controles.

Agora sobre os cárceres privados em si, eu não sei bem o que dizer, me parece estranho este fenómeno no Brasil porque nos Estados Unidos da América, onde há mais controle sobre os cárceres, eles estão abandonando este modelo. Isso porque não pareceu para eles que este fosse um bom negócio. Eles preferiram vender armas, enfim, fazer outros negócios que pudessem ter ganancias maiores. Se os cárceres privados vão a ser efetivamente controlados, o capital vai fugir destas, não vai se interessar. O problema é justamente quando aceitam estas para se fazer de qualquer forma, se promulgar qualquer coisa dentro delas, sobretudo porque assim se pode aumentar a violência, porque é mais barato ter menos funcionários, ou que estes sejam menos capacitados, se colocar os internos em piores condições de vida ou de fornecimento de alimentos. Esse é o perigo de não controlar estes capitais privados vinculados com esta vocação estatal de castigar.

\section{Entrevistadoras:}

E por fim, uma última pergunta. Nós sabemos que não há uma resposta sucinta e direta, mas gostaríamos de saber se hoje você fosse o responsável por colocar em pratica um plano de gestão pública, o que acredita que seriam as medias cruciais de segurança?

\section{Gabriel Anitua:}

Creio que seria pouco ambicioso. Não se pode fazer um plano que solucione tudo pporque isso já de entrada é uma mentira. Se eu fosse assessor de um político de segurança, o primeiro que eu lhe diria seria: "não digam que irão solucionar rapidamente algo ou que vocês têm uma ideia genial. Não se pode fazê-lo". Não se pode e além de tudo se irá acabar 
com as expectativas e a legitimidade de um programa. O que se deve fazer são políticas concretas e pequenas. Se temos um problema em que morrem muita gente nas estradas e rodovias, então temos que pensar em um sistema de controle de velocidade, e pode ser que com os anos isso reduza o número de mortandade. Reduzir esta violência no trânsito é o que se deve buscar solucionar neste caso.

Pode-se fazer também uma política de uso adequado das armas de fogo por parte da polícia, isso também é uma possibilidade. Colocando mais controle e saber que as armas que os policiais utilizam.

O que se pode fazer são políticas muito centradas, com objetivos concretos sem essa ambição de "quero solucionar tudo", porque isso é mágica, não são temas fáceis, isso não existe. $\mathrm{E}$ é claro que existem muitas coisas, me ocorreram essas duas ideias mas existem inúmeras maneiras de se trabalhar. Penso eu que é muito necessário se pensar concretamente em como reduzir a violência, para que hajam menor mortos. Se busca reduzir a violência, também na que envolve a penitenciaria que necessita de muita coisa, claro, como a redução do número de presos que vai implicar numa melhora, como a melhora do sistema educativo nas prisões, dos traslados arbitrários, vai melhorar a alimentação, os programas de atenção psiquiátrica. Como destaquei, há muitas coisas para fazer, mas como eu disse, precisam ser bem concretas para poder melhorar todo este fenômeno da questão criminal.

\section{Entrevistadoras:}

Bom, é isso Gabriel. Muito obrigada por nos conceder esta entrevista. Foi um privilégio podermos debater estes assuntos com você.

\section{Gabriel Anitua:}

Imaginem. Eu que Ihes agradeço pelas perguntas. Um abraço.

(Recebido para publicação em janeiro de 2019)

(Reapresentado em fevereiro de 2019)

(Aprovado para publicação em maio de 2019)

\section{Cite esta entrevista}

ANITUA, Gabriel, 2019. Entrevista conduzida por Tamires Alves e Gabriela Gusis. Revista Estudos Políticos: a publicação semestral do Laboratório de Estudos Hum(e)anos (UFF).Rio de Janeiro, Vol.10 |N.1, pp.4-16, maio de 2019.

\section{Notas}

1. Operação Lava a Jato em Curso no Brasil investiga políticos e empresários envolvidos em licitações fraudulentas e desvios de verba.

2. Livro de Erdwin Sutherland: Crimes de Colarinho Branco.

3. Operação Mãos Limpas realizada na Itália em 1992, investigou políticos, empresários, mas principalmente os setores mais a esquerda. Prendeu 2993 pessoas e inseriu 
o país numa das suas maiores crises econômicas e políticas já enfrentadas. 
